Article available at http://www.parasite-journal.org or nttp://dx.dol.org/10.1051/parasite/2012192173

\title{
EPIDEMIOLOGICAL SURVEY OF ANTI-FLEA IGE IN DOGS IN JAPAN BY USING AN ANTIGEN-SPECIFIC IGE QUANTITATIVE MEASUREMENT METHOD
}

\author{
ICHIKAWA Y.* \& BEUGNET F.**
}

\section{Summary:}

In Japan, an epidemiological survey was performed in dogs from October to December 2008 by using a quantitative measurement method for antigen-specific IgE towards specific Ctenocephalides felis antigens. 214 dogs from 22 veterinary clinics were included. These clinics were located as follows, from North to South: Hokkaido, Aomori, Fukushima, Tochigi, Saitama, Chiba, Tokyo (Tama-City and Ota-ku), Kanagawa, Gifu, Niigata, Kyoto, Nara, Osaka, Hyogo, Kagawa, Ehime, Hiroshima, Yamaguchi, Fukuoka, Kumamoto and Kagoshima. 110 dogs (51.4\%) were seropositive for flea-specific IgE. No differences were associated with gender or breed. This survey confirms that flea infestation in dogs is a common problem in Japan. It especially shows that the infestation also occurs in Northern Japan where fleas are considered uncommon by the vet.

KEY WORDS: dog, flea, epidemiology, serology, Japan.
Résumé : ÉTUDE ÉPIDÉMIOLOGIQUE DES RÉPONSES SÉROLOGIQUES IG-E ANTI-PUCES CHEZ LES CHIENS, AU JAPON, PAR UTILISATION D'UNE MÉTHODE DE MESURE SPÉCIFIQUE ET QUANTITATIVE

Une étude épidémiologique a été conduite au Japon entre octobre et décembre 2008 sur des chiens par utilisation d'une méthode sérologique quantitative mesurant la réponse lg-E anti-puces. 214 chiens ont été prélevés dans 22 cliniques vétérinaires. Ces cliniques sont situées, du nord au sud, dans les cantons de: Hokkaido, Aomori, Fukushima, Tochigi, Saitama, Chiba, Tokyo (Tama-City et Ota-ku), Kanagawa, Gifu, Niigata, Kyoto, Nara, Osaka, Hyogo, Kagawa, Ehime, Hiroshima, Yamaguchi, Fukuoka, Kumamoto et Kagoshima. 110 chiens (51,4\%) étaient séropositifs vis-à-vis des Ig-E spécifiques de l'allergène puce. Aucune différence n'est associée au sexe ou à la race. Cette étude confirme que l'infestation des chiens par les puces est un problème courant au Japon. Elle démontre également que les infestations par les puces existent dans le nord du Japon, où les puces sont parfois considérées comme absentes par les vétérinaires.

MOTS-CLÉS : chien, puce, épidémiologie, sérologie, Japon.

serological response to flea allergens. Seropositivity is a valid proof of a flea bite, even if the time (recent or old infestation) as well as the degree of infestation cannot be established.

Cat flea allergens are high-molecular proteins found in flea saliva (McDermott et al., 2000). Cat flea salivary extracts also show great antigenic diversity recognized by IgE from artificially sensitized dogs or from those with FAD (Lee et al., 1999). McDermott et al. cloned a major $18-\mathrm{kD}$ allergen, called Cte $\mathrm{f} 1$ in the international nomenclature (Medleau et al., 2003). Its structure is very similar to that of the original molecule in terms of flea IgE-binding (Medleau et al., 2003).

Intradermal testing is the standard method for identifying IgE-mediated allergic reaction in vivo, but it requires specific equipment and manipulation in each veterinary clinic (Laffort-Dassot et al., 2004). At the opposite, specific serum IgE measurement can be performed in a well-equipped laboratory and requires only a blood sample at the veterinary clinic level. As for intradermo-reaction/prick tests, it is intended to reveal the current sensitization level to flea allergens. In this survey, serum concentration of antigenspecific IgE was quantitatively measured in $\mathrm{ng} / \mathrm{mL}$ using a published technique (Okayama et al., 2010). The specificity of this technique has been previously

* Merial Japan Limited, 2-14-2 Nagata-cho, Chiyoda-ku, Tokyo 1000014, Japan. E-mail: yasuaki.ichikawa@merial.com.

** Merial, 29, avenue Tony Garnier, 69007 Lyon, France.

Correspondence: Frédéric Beugnet.

E-mail: frederic.beugnet@merial.com 
controlled by using several antigens (flea and pollens), experimental dogs that were not sensitized and experimental dogs that were sensitized. The assay enables to monitor serum antigen-specific IgE concentrations in dogs, providing information on flea exposure (Fujimura et al., 2011).

\section{MATERIALS AND METHODS}

S erum concentration of $\mathrm{IgE}$ against flea antigens was measured in this epidemiological study in dogs in Japan. 22 veterinary clinics were recruited throughout Japan districts to get an estimation of flea burden on dogs (Fig. 1). All veterinary clinics were asked to randomly recruit ten dogs and collect a blood sample during the period from August to October 2008. The selected dogs had to be healthy and were not to show any clinical signs, especially dermatosis and pruritus. All dogs were client-owned and presented to the animal hospitals for routine check-ups. The age of the dogs ranged from two to seven years. A total of 214 blood samples were collected. The profiles of the dogs examined are shown in Table I.

Serum samples from dogs were collected from October to December 2008 in the following 22 areas: Hokkaido, Aomori, Fukushima, Tochigi, Saitama, Chiba, Tokyo (Tama-City and Ota-ku), Kanagawa, Gifu, Niigata, Kyoto, Nara, Osaka, Hyogo, Kagawa, Ehime, Hiroshima, Yamaguchi, Fukuoka, Kumamoto and Kagoshima (Fig. 1).

The allergen-specific IgE quantitative measurement was performed by Animal Allergy Clinical Laborato-

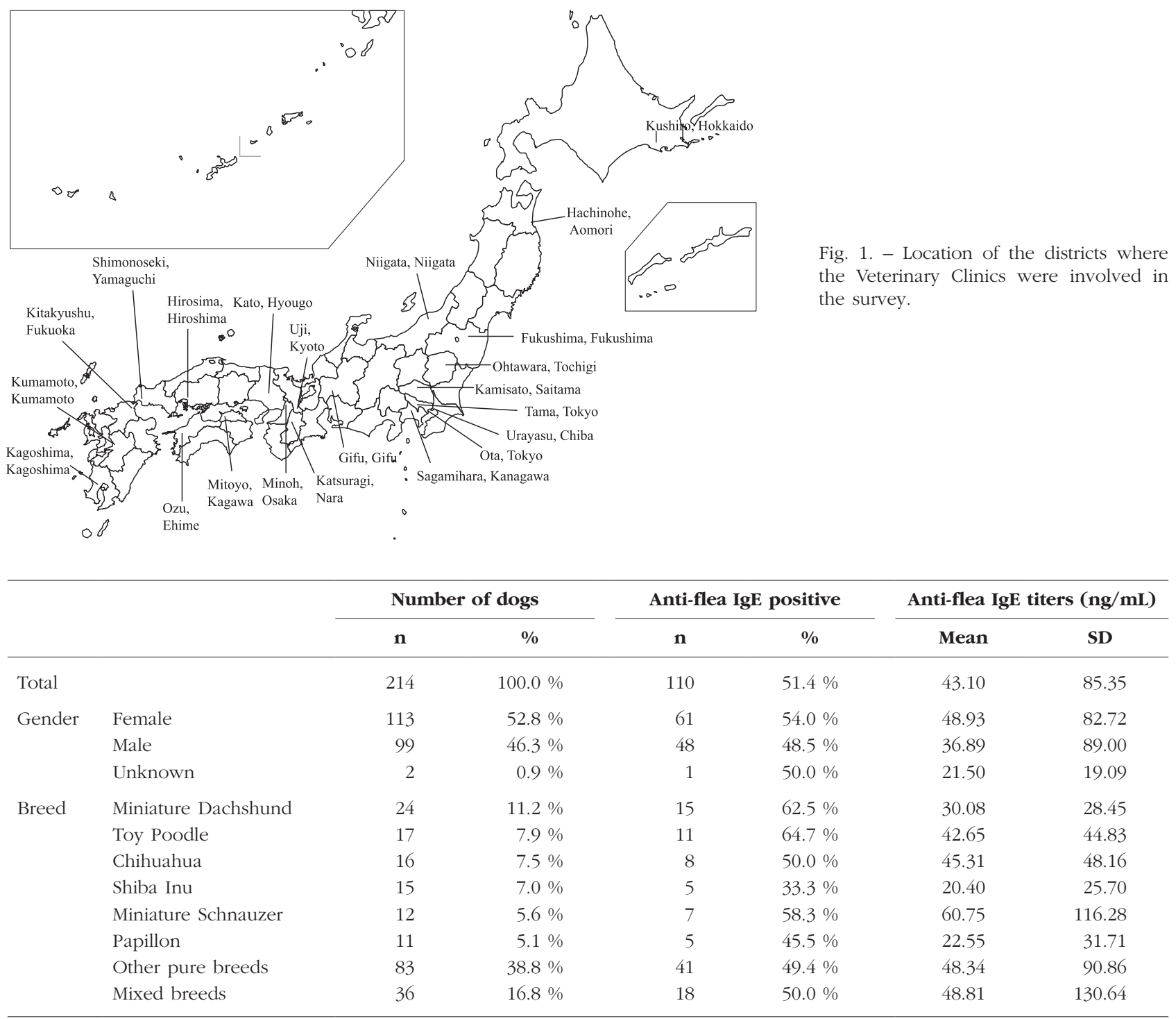

Table I. - Profile and IgE positive rate in the 214 examined dogs. 
ries, Inc (Kanagawa, Japan), according to a procedure previously published (Okayama et al., 2010). In short, 40 kinds of allergen-IgE including 22 environmental allergens and 18 food allergens were measured in this assay. The antigen of flea whole body was purchased from Greer Laboratories, Inc. (Lenoir, NC, USA) and used in this assay. Prior to the study, flea-specific IgE concentrations were measured in four experimental healthy Beagle dogs (two females of five-month-old and two males of four-month-old) kept in a flea-freecontrolled facility. The values obtained were respectively $0,3,2$ and $13 \mathrm{ng} / \mathrm{mL}$, with an average of 4.5 and a standard deviation of 5.8. The cut off was calculated as mean $+2 \mathrm{SD}=16 \mathrm{ng} / \mathrm{mL}$.

Then, based on previously published (McDermott et al., 2000) assessments, we estimated flea IgE positive when data showed $>16 \mathrm{ng} / \mathrm{mL}$ for flea IgE.

The total IgE half-life is considered to be short (12 hours in mice to two days in humans) (Hirano et al., 1983; Tizard, 2009). However, IgE production from plasma cells seemed to continue for several months and serum antigen-specific IgE was detected during off-season of offending allergen (Masuda et al., 2002; Tizard, 2009). It was therefore hypothesized that a positive result would indicate a current or past flea exposure with no possibility to a precise estimation of the flea infestation status.
Cross-reactivity of IgE against house dust mites may influence flea-IgE titers. Therefore, all the cases with coincidental sensitization to house dust mites, i.e. when the IgE against house dust mites (Dermatophagoides farinae and/or Dermatophagoides pteronyssinus) was higher than flea-IgE, were excluded from this study.

The statistical analysis used was the Steel-Dwass' test with IgE values according to gender, breed (if, $\mathrm{n}>10$ ) and area with a significance level of $p<0.05$. This survey was undertaken from October to December 2008, which only covers the end of the entire flea season. As it was not conducted throughout the whole year, a season analysis per region could not be conducted.

\section{RESULTS}

T lable I shows the results by gender and breed. No significant differences were observed in both data sets $(p>0.05)$. Based on gender, $54.0 \%$ of female dogs (61/113) and $48.5 \%$ of male dogs (48/99) were positive for flea IgE. Based on breed, $62.5 \%$ of Miniature Dachshunds $(n=24), 64.7 \%$ of Toy Poodles $(n=17), 50.0 \%$ of Chihuahuas $(n=16), 33.3 \%$ of Shiba Inus $(\mathrm{n}=15), 58.3 \%$ of Miniature Schnauzers $(n=12), 45.5 \%$ of Papillons $(n=11), 49.4 \%$ of other

\begin{tabular}{|c|c|c|c|c|c|}
\hline \multirow[b]{2}{*}{ Area } & \multirow{2}{*}{$\begin{array}{l}\text { Number } \\
\text { of dogs }\end{array}$} & \multicolumn{2}{|c|}{ Anti-flea IgE positive } & \multicolumn{2}{|c|}{ Anti-flea IgE titers $(\mathrm{ng} / \mathrm{mL})$} \\
\hline & & $\mathbf{n}$ & $\%$ & Mean & SD \\
\hline Kushiro, Hokkaido & 10 & 3 & $30.0 \%$ & 10.50 & 15.67 \\
\hline Hachinohe, Aomori & 10 & 6 & $60.0 \%$ & 43.90 & 47.67 \\
\hline Fukushima, Fukushima & 10 & 1 & $10.0 \%$ & 35.90 & 100.64 \\
\hline Ohtawara, Tochigi & 10 & 6 & $60.0 \%$ & 54.80 & 70.77 \\
\hline Kamisato, Saitama & 10 & 8 & $80.0 \%$ & 30.10 & 18.02 \\
\hline Urayasu, Chiba & 10 & 4 & $40.0 \%$ & 29.60 & 37.93 \\
\hline Tama, Tokyo & 8 & 4 & $50.0 \%$ & 84.63 & 124.20 \\
\hline Ota, Tokyo & 10 & 7 & $70.0 \%$ & 31.70 & 27.56 \\
\hline Sagamihara, Kanagawa & 10 & 5 & $50.0 \%$ & 33.30 & 44.40 \\
\hline Niigata, Niigata & 10 & 5 & $50.0 \%$ & 29.30 & 36.93 \\
\hline Gifu, Gifu & 10 & 1 & $10.0 \%$ & 4.70 & 6.20 \\
\hline Uji, Kyoto & 10 & 7 & $70.0 \%$ & 69.80 & 121.85 \\
\hline Minoh, Osaka & 6 & 3 & $50.0 \%$ & 16.50 & 12.41 \\
\hline Kato, Hyougo & 10 & 7 & $70.0 \%$ & 109.60 & 224.23 \\
\hline Katsuragi, Nara & 10 & 8 & $80.0 \%$ & 92.30 & 122.73 \\
\hline Hirosima & 10 & 3 & $30.0 \%$ & 13.60 & 15.56 \\
\hline Shimonoseki, Yamaguchi & 10 & 6 & $60.0 \%$ & 32.40 & 32.09 \\
\hline Mitoyo, Kagawa & 10 & 4 & $40.0 \%$ & 16.60 & 18.59 \\
\hline Ozu, Ehime & 10 & 4 & $40.0 \%$ & 30.50 & 43.11 \\
\hline Kitakyushu, Fukuoka & 10 & 3 & $30.0 \%$ & 10.40 & 13.37 \\
\hline Kumamoto, Kumamoto & 10 & 6 & $60.0 \%$ & 32.40 & 30.99 \\
\hline Kagoshima, Kagoshima & 10 & 9 & $90.0 \%$ & 133.40 & 158.90 \\
\hline Total & 214 & 110 & $51,4 \%$ & & \\
\hline
\end{tabular}

Table II. - Results of anti flea-IgE by area. 
pure breeds $(n=83)$ and $50.0 \%$ of mixed breeds $(n=$ 36) were positive for anti-flea IgE, respectively.

Positive rates of anti-flea $\operatorname{IgE}$ in areas examined in this study were $51.4 \%(110 / 214)$. Cases with anti-flea IgE were found in all 22 areas surveyed in this study. The prevalence of seropositive dogs from Northern to Southern Japan was: $30 \%$ in Hokkaido (3/10 dogs), $60 \%$ in Aomori (6/10 dogs), $10 \%$ in Fukushima (1/10 dogs), $60 \%$ in Tochigi (6/10 dogs), $80 \%$ in Saitama (8/10 dogs), $40 \%$ in Chiba (4/10 dogs), $50 \%$ in Tama-City, Tokyo (4/8 dogs), $70 \%$ in Ota-Ku, Tokyo (7/10 dogs), $50 \%$ in Kanagawa (5/10 dogs), $10 \%$ in Gifu (1/10 dogs), $10 \%$ in Niigata (1/10 dogs), $70 \%$ in Kyoto ( $7 / 10$ dogs), $80 \%$ in Nara (8/10 dogs), $50 \%$ in Osaka (3/6 dogs), $70 \%$ in Hyogo (7/10 dogs), $30 \%$ in Hiroshima (3/10 dogs), $60 \%$ in Yamaguchi $(6 / 10$ dogs), $40 \%$ in Kagawa (4/10 dogs), $40 \%$ in Ehime (4/10 dogs), $30 \%$ in Fukuoka (3/10 dogs), $60 \%$ in Kumamoto (6/10 dogs) and $90 \%$ in Kagoshima (9/10 dogs). Significant differences were present between areas, regarding positive rates or mean $\operatorname{IgE}$ values at $\mathrm{p}<0.05$ (Table II).

\section{DISCUSSION}

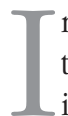
$\mathrm{n}$ all, $51.4 \%$ of dogs living in Japan were seropositive for anti-flea IgE meaning that they were either infested by fleas several weeks prior to survey dates or that they remained infested.

As expected, we did not find any significant differences in gender and breed. Significant differences were present among areas, but the interpretation of the data is difficult due to the low number of samples. It will be necessary to include more dogs in a future study, to collect samples throughout a whole year in order to evaluate the seropositivity during the four seasons, and to take into account the impact of regular or occasional anti-flea treatments.

In this time-limited study, we confirmed that dogs were often infested and bitten by fleas in Japan. We found solid proof that fleas are present in cold Northern areas, through the positivity rate of dogs that haven't travelled around the country, despite the fact that vets and pet owners believe that fleas cannot be found in those regions. Climate change may explain the higher flea prevalence in the North, as it has also been shown for other insects. In Hokkaido, cockroaches and beetles were rarely found several decades ago but they have now increased significantly in numbers (Kida, 2007). This survey also highlights the importance of controlling fleas, given that more than $50 \%$ of dogs were infested with them. Future surveys will assess the impact of monthly flea treatments on this serological status.

\section{ACKNOWLEDGEMENTS}

VTe wish to thank the 22 animal hospitals as well as the dog owners for their supply of canine serum samples.

\section{REFERENCES}

BEugnet F. \& FRANC M. Results of a european multicentric field efficacy study of fipronil-(S) methoprene combination on flea infestation of dogs and cats during 2009 summer. Parasite, 2010, 17, 337-342.

Farkas R., Gyurkovszky M., Solymosi N. \& Beugnet F. Prevalence of flea infestation in dogs and cats in Hungary combined with a survey of owner awareness. Medical and Veterinary Entomology, 2009, 23, 187-194.

Fujimura M., Masuda K., Hayashiya M. \& Okayama T. Flow cytometric analysis of lymphocyte proliferative responses to food allergens in dogs with food allergy. J Vet Med Sci, 2011, 73 (10), 1309-1317.

Hirano T., Ho C. \& Ovary Z. Half-life of murine IgE antibodies in the mouse. Int Arch Allergy Appl Immunol, 1983, 71, 182-184.

KIDA Y. Hokkaido no Kabutomushi. Hokkaido Nature Magazine Mally, 2007, 17, 28-30 (in Japanese).

LeE S.E., Johnstone I.P., LeE R.P. \& Opdebeeck J.P. Putative salivary allergens of the cat flea, Ctenocephalides felis felis. Vet Immunol Immunopathol, 1999, 69, 229-237.

LafFort-Dassot C., Cartotti D., Pin D. \& Jasmin P. Diagnosis of flea allergy dermatitis: comparison of intradermal testing with flea allergens and a FceRI $\alpha$-based IgE assay in response to flea control. Vet Dermatol, 2004, 15, 321-330.

Masuda K., Sakaguchi M., Saito S., Yamashita K., Hasegawa A., Ohno K. \& Tsujıмото H. Seasonal atopic dermatitis in dogs sensitive to a major allergen of Japanese cedar (Cryptomeria japonica) pollen. Vet Dermatol, 2002, 13, 55-61.

McDermott M.J., Weber E., Hunter S., Stedman K.E., Best E., Frank G.R., Wan R., Escudero J., Kuner J. \& McCall C. Identification, cloning, and characterization of a major cat flea salivary allergen (Cte f 1). Mol Immunol, 2000, 37, 361-375.

Medleau L., Clekis T., McArthur T.R., Alva R., Barrick R.A., JEANNIN P. \& IRWIN J. Evaluation of fipronil spot-on in the treatment of flea allergic dermatitis in dogs. J Small Anim Pract, 2003, 44, 71-75.

Okayama T., Matsuno Y., Yasuda N., Tsukui T., Suzuta Y., Koyanagi M., Sakaguchi M., Ishil Y., Olivery T. \& Masuda K. Establishment of a quantitative ELISA for the measurement of an allergen-specific IgE in dogs using antiIgE antibody cross-reactive to mouse and dog IgE. Vet Immunol Immunopath, 2010, 139, 99-106.

TIZARD I.R. Type I hypesensitivity, in: Veterinary Immunology $8^{\text {th }}$ ed. Saunders, St. Louis, Missouri, 2009, 329-346.

Received on November $7^{\text {th }}, 2011$ Accepted on March $13^{\text {th }}, 2012$ 